УДК 161.11

DOI:

10.15372/PS20150306

\author{
А.C. Кашпурова \\ Институт философии и права СО РАН, г. Новосибирск, \\ kashpurovaafina@gmail.com \\ ОБЛАДАЕТ ЛИ БЕССОЗНАТЕЛЬНОЕ \\ МЕНТАЛЬНЫМ СОДЕРЖАНИЕМ?
}

Рассматривается взаимоотношение концептов подсознания и бессознательного. Обосновывается избыточность понятия бессознательного для нужд психологии, поскольку бессознательное не обладает ментальным содержанием.

Ключевые слова: подсознание, сознание, мышление, мыслительный процесс, мыслительный акт

\author{
A.S. Kashpurova \\ Institute of Philosophy and Law SB RAS, Nikolaeva str, 8, Novosibirsk, 630090, Russia \\ kashpurovaafina@gmail.com
}

\title{
DOES THE UNCONSCIOUS POSSESSES MENTAL CONTENT?
}

In this article was considered the concepts' relationship of subconsciousness and unconscious. There were proved redundancy of concept unconscious for psychology needs, because the unconscious doesn't possess the mental contents locates.

Keywords: consciousness, mind, subconscious, thinking, act of thought, thinking process.

Понятия подсознания и бессознательного уже достаточно давно прочно вошли в научный и даже философский обиход. Критика классической философии, отягощенной метафизическим концептуальным каркасом идеализма, в свое время велась не только с позиций логики и философии языка, но и с позиций психологии, настаивавшей на том, что свойства и структуры человеческой психики не сводятся к свойствам и структурам феноменальных данностей сознания. Однако увлечение использованием категорий подсознательного и бессознательного оказа-

(C) Кашпурова А.А., 2015 
лось столь велико и труднопреодолимо, что теоретические конструкции, основанные на этих категориях, стали вторгаться в чуждые им области, например в сферу эпистемологии, на том основании, что познание является психическим процессом. Подобный способ психологизации теоретико-познавательного дискурса сыграл негативную роль в философии науки, дав карт-бланш иррационалистическим оъяснениям.

Вот как описывает этот процесс В.П. Зинченко: «Одни из первых представлений о структуре сознания принадлежат 3. Фрейду. Его иерархическая структура: подсознание, сознание, сверхсознание - видимо, уже исчерпала свой объяснительный потенциал. Несмотря на то что в этой структуре именно на подсознание ложится основная функция в объяснении целостного сознания, многим поколениям психоаналитиков и психологов не удалось нащупать удовлетворительных путей проникновения в подсознание. В настоящем контексте существенно подчеркнуть, что речь идет не о критике Фрейда и тем более не об отрицании подсознания. Оно представляет собой хорошо известный эмпирический феномен, описанный задолго до Фрейда как вестибюль (или подвал) сознания. Более того, наличие категории и феноменов бессознательного и подсознания представляет собой непреодолимую преграду для любых форм редукции психического. Речь идет о том, чтобы найти новые пути к анализу сознания, когда подсознание и бессознательное вообще не обязательны как средство (и тем более как главная цель) в изучении сознания. В теоретико-познавательном плане подсознание давно стало подобием некоторой емкости, в которую погружается все непонятное, неизвестное, загадочное или таинственное, например интуиция, скрытые мотивы поведения, неразгаданные смыслы и т.п.» ${ }^{1}$ [Зинченко, 1991. - С. 15]. И далее: «Можно надеяться, что такое пренебрежение подсознанием не вызовет неудовольствия у специалистов в области психоанализа. Они ведь и сами решают задачу извлечения событий из подсознания, перевода их в сознание, а не погружения, выталкивания или вытеснения их из сознания в подсознание. С последней процедурой многие справляются своими силами, без помощи психоаналитиков, и притом достаточно успешно (курсив наш. - A.K.)»² [Зинченко, 1991. - С. 15].

На вытеснение в подсознание неких событий, а точнее, функций и процессов хотелось бы обратить особое внимание, впрочем, несколько

${ }^{1}$ Зинченко В.П. Миры сознания и структура сознания // Вопросы психологии. - 1991.№ 2. - C. 15 .

\footnotetext{
${ }^{2}$ Там же.
} 
сместив акцент. Дело в том, что обычно психологи предпочитают рассуждать о вытеснении травматических воспоминаний, однако это всего лишь частный случай вытеснения. Существует гораздо более обширный класс процессов, которые вытесняются, а именно, повседневные когнитивные операции, которые «сбрасываются» в подсознание в целях автоматической обработки. Следует иметь в виду, что можно успешно осуществлять такой сброс не только в подсознание, но и на внешние технические устройства. Подобных взглядов придерживается Д. Деннет. Мышление, согласно философской доктрине Деннета, функционирует по принципу вытеснения когнитивных задач в окружающую среду при условии, что в ней существуют устройства, способные хранить и перерабатывать информацию. «Полагаю, - пишет он, - что первопричиной служит наша привычка выгружать как можно больше когнитивных задач в саму окружающую среду - вытеснять наши мысли (т.е. наши мыслительные проекты и деятельность) в окружающий нас мир, в котором масса создаваемых нами периферийных устройств может хранить, перерабатывать и по-новому представлять наши смыслы, направляя, усиливая и защищая процессы преобразования, которые и есть наше мышление» ${ }^{3}$ [Деннет, 2004. - С. 58].

Провозглашается ориентация мышления на окружающий мир. Субъект обладает потребностью «выгружать» информацию посредством ведения дневника, блога и т.д. Однако Д. Деннет упускает существенный момент: информация может «выгружаться» не только во внешний мир, но и внутрь ментального мира субъекта (подсознание). Известны ситуации, когда в экстремальных обстоятельствах сознание не успевает обработать полученную информацию. Однако после осуществления акта восприятия полученная на входе информация записывается в подсознание и память.

Д. Деннет не рассматривает явным образом подсознание в качестве такого рода «внешнего» устройства, хотя его концепция оставляет подобную возможность: «Умы являются композициями из инструментов мышления». Эта возможность была проанализирована Э. Кларком и Д. Чалмерсом в статье «Распределенный разум» («The extended mind») в 1994 году. Данные авторы полагают, что когнитивные акты не являются с необходимостью ограниченными пределами тела и, соответственно, пределами феноменальной части психики, которую часто отождествляют с сознанием. Они предлагают провести мысленный эксперимент,

${ }^{3}$ Деннет Д. Виды психики. - М.: Идея-Пресс. - 2004. - С. 58. 
поразмышлять над тремя воображаемыми ситуациями. Первая ситуация: субъект смотрит на нарисованную проекцию трехмерной фигуры и ему надо нарисовать три проекции этой фигуры на бумаге. Чтобы выполнить эту задачу, он должен представить фигуру и мысленно ее повращать. Вторая ситуация: субъект сидит перед компьютером и видит на экране проекцию трехмерной фигуры. Для выполнения аналогичной задачи ему достаточно нажать нужную кнопку. Третья ситуация: субъект помещен в первую ситуацию, но ему в мозг встроили кибернетический имплант, рассчитывающий проекции фигуры и отображающий ее в зрительной коре субъекта ${ }^{4}$ [Clark, Chalmers, 1998. - С. 10].

Вот как интерпретирует взгляды этих авторов Д.В. Винник: «Для Кларка и Чалмерса все три ситуации идентичны с точки зрения когнитивных операций самих по себе: “не имеет ровно никакого значения, где эти операции реализованы в действительности”. Согласно метафоре этих авторов, “когнитивные акты просачиваются в тело и в окружающий мир”. Сознание находится в пределах черепа, однако оно может быть расширено за счет усвоения инструментов из внешней среды (от блокнота и карандашей до смартфонов и модулей памяти» ${ }^{5}$ [Винник, 2010. - С. 126].

Впрочем, данная онтологическая концепция при всей своей привлекательности слишком радикальна. Обычно ее именуют радикальнылм экстернализмом. Понятно, что подсознание, а точнее, определенные структуры мозга можно рассматривать как внешние по отношению к сознанию устройства, но неверно было бы считать, что источники наших мыслительных актов лежат во внешнем мире в изначальном смысле этого слова. Субъекту свойственно рефлексировать и обращаться к своим сформированным индивидуальным жизненным установкам. Подсознание играет немаловажную роль в формировании этих установок, которые могут являться отправными точками мыслительного акта.

Американский философ и психолог У. Джеймс утверждал: «Мышление всегда связано с личным интересом» ${ }^{6}$ [Джеймс, 1991. - С. 250]. Эта философская позиция является противовесом позиции Д. Деннета, так как интерес - индивидуальная потребность субъекта получать ин-

\footnotetext{
${ }^{4}$ Cм.: Clark A., Chalmers D. The extended mind // Analysis. - 1998. - No. 58 (1). - P. 7-19.

${ }^{5}$ Винник Д.В. Сознание за пределами мозга: Истоки аргументации радикального экстернализма // Вестник ТГУ. Сер.: Философия. Социология. Политология. - 2010. - № 2. C. $125-136$.

${ }^{6}$ Джееймс У. Психология. - М.: Педагогика. - 1991. - С. 250.
} 
формацию об объекте или другом субъекте. Интерес за счет индивидуальности исходит из ментального мира субъекта. Субъект ищет то, что ему интересно, определяет ход своей деятельности в рамках своих интересов. Структура аргументации при построении мыслительного акта пропитана интересом субъекта, а потому есть возможность через ход рассуждения понять не только мыслимый объект, но и субъекта, его осмысливавшего. Возникновение интереса к любой деятельности обусловлено индивидуальным жизненным опытом, которым обладает субъект. Подобную точку зрения можно встретить у Б. Спинозы: «Всякая вещь может быть косвенной причиной удовольствия, неудовольствия и желания» ${ }^{7}$ [Спиноза, 2015. - С. 173].

Обращаясь к своему внутреннему миру, субъект заимствует исходные позиции для инициации актов мышления. Подсознание может участвовать в обработке полученной извне информации, трансформируя ее в ментальные состояния прочих типов и установки. Можно согласиться с Д. Деннетом в том, что мышлению необходимы вспомогательные элементы. Однако его утверждение, что все вспомогательные элементы находятся в окружающем мире, является радикальной идеей. Интересы, если пользоваться терминологией Деннета, можно считать своеобразными ориентирами мышления, но только не размещенными вовне, а заключенными в самом сознании или подсознании.

Мышление - это продуктивный процесс, направленный на формирование выводов о мире на основе анализа и синтеза опытных данных. Будучи процессом продуктивным, мышление всегда осуществляется, опираясь на определенные исходные данные и интересы субъекта, так как для достижения итога мыслительного акта необходимы отправные точки, с которых начинается мыслительный процесс.

Представляется очевидным наличие влияния подсознания на мыслительный акт, однако целесообразно рассмотреть понятия «бессознательное» и «подсознание» и произвести их демаркацию. Проведение границы между этими понятиями позволяет увидеть, возможно ли влияние бессознательного на мыслительные процессы.

Понятие подсознания по своему онтологическому статусу менее обширное, чем понятие бессознательное. Подсознание существует благодаря бессознательному, оно «живет» в его сфере. Исключительно благодаря возможности мозга осуществлять большинство процессов тайно от сознания существует подсознание как часть психики. Важно пони-

${ }^{7}$ Спиноза Б. Этика. - СПб.: Азбука. - 2015. - С. 173. 
мать, что мозг не занят только психическими процессами. Следует обратить внимание на то, что под психикой понимается явление, возможное благодаря строению головного мозга и, в свою очередь, делающее возможным многоуровневое взаимодействие субъекта с миром. В отличие от подсознания, бессознательное по определению является недоступным для сознания. Бессознательное скрывает от сознания все те процессы, которые происходят в организме, в том числе и те, которые обусловливают наличие сознания и подсознания. Бессознательное представляет собой совокупность физиологических процессов, репрезентация которых невозможна в сознании. Это прежде всего психофизические процессы.

Исследователи сознания имеют возможность установить каузальную связь между бессознательным процессом и процессом сознательным, который, в свою очередь, детерминирован бессознательным. В психологии были предприняты попытки нагрузить бессознательное психическим содержанием, например в аналитической психологии К.Г. Юнга - в форме архетипов коллективного бессознательного. Однако попытка Юнга выродилась в огромное количество спекуляций мистического характера. Юнг утверждает, что «содержания коллективного бессознательного не контролируются волей и ведут себя так, словно никогда в нас и не существовали - их можно обнаружить у окружающих, но только не в самом себе» ${ }^{8}$ [Юнг. - С. 35]. Таким образом, он позиционирует бессознательное как некое хранилище архетипов. Однако в таком случае происходит подмена понятия. Бессознательное не обладает психическим содержанием, оно не содержит архетипов, образов, символов. Бессознательное - функция, скрывающая процессы мозга от сознания, которые просто не должны быть репрезентированы. Подсознание же- это хранилище чувств, эмоций, симпатий и антипатий субъекта, и оно есть часть психики.

Первое упоминание об уровнях психики, недоступных сознанию принадлежит Г. Лейбницу. Вот как он описывает эту идею в своем трактате «Монадология»: «большое количество малых восприятий, в которых нет ничего различного» ${ }^{9}$ [Лейбниц, 1982. - С. 415]. Выходя из состояния бессознательного, мы можем говорить о том, что с нами было до этого и что происходит сейчас. Если «придя в себя из бессознательного

\footnotetext{
${ }^{8}$ Юнг К.Г. Аналитическая психология: Тавистокские лекции. - СПб.: Кентавр, 1994. C. 35 .

${ }^{9}$ Лейбнии Г.В. Монадология // Лейбниц Г.В. Сочинения: В 4 т. - М.: Мысль, 1982.T. 1.-C. 415 .
} 
состояния, мы сознаем наши восприятия, то последние необходимо должны были существовать и непосредственно перед тем, хотя бы мы и вовсе не сознавали их, ибо восприятие может естественным путем произойти только от другого восприятия, как и движение естественным путем может произойти только из движения» ${ }^{10}$ [Лейбниц, 1981. - С. 416].

Г. Лейбниц наделял бессознательное психическим содержанием, приравнивая его к низшей форме душевной деятельности. Подобное философское объяснение продиктовано духом времени творчества Лейбница, господствовавшим тогда идеалистическим представлением о том, что такое бессознательное и что такое сознание. Естественно, что во времена Лейбница не было установлено каузальной связи между психической деятельностью и головным мозгом. Обнаружение и описание каузальной связи между мозгом и сознанием позволили понять, что содержание бессознательного недоступно для репрезентации в сознание. Большинство процессов в мозге происходят незаметно не только для сознания, но и подсознания.

Существует жестко определенная граница между тем, что репрезентируется, что может быть репрезентировано и что не подвергается операции репрезентации. Отсутствие психического содержания у бессознательного не предполагает отказ от постулирования существования второй сцены в ментальном мире субъекта. Отрицание наличия некоего хранилища чувств, символов и т.д., влияющих на мыслительные акты, представляется бессмысленным. Если отказать подсознанию в онтологическом статусе, это откроет возможность для идеалистических спекуляций на основе различного рода внезапных идей, которые могут появляться у субъекта. Исключительно на этом основании вводится понятие подсознательного как части психики, которая функционирует вместе с сознанием. Нестрогость терминологического аппарата может быть устранена при четком определении элементов, которые позволяют психике функционировать таким образом, чтобы субъект имел возможность взаимодействовать с миром.

Первая попытка объяснить бессознательное с материалистических позиций принадлежит английскому психологу Д. Гартли, который связал бессознательное с деятельностью нервной системы. Для обоснования своей идеи Гартли привлек вибрационную теорию, он предположил, что вся психическая деятельность обусловлена работой организма как машины. Головной мозг представлен как вмещающий в себя память, вни-

\footnotetext{
${ }^{10}$ Там же. - С. 416.
} 
мание, воображение, мышление - все умственные способности человека. Позиция Гартли нашла отклик у ученых и впоследствии была развита на основе исследований работы головного мозга ${ }^{11}$ [Гартли, 1967].

Важно понимать, что в бессознательном нет символов, образов, перцепций. Нагрузка бессознательного содержанием подсознательного приводит в смешению совершенно разных сущностей. Подобный подход не позволяет понять, какому влиянию может подвергнуться мыслительный процесс как процесс, протекающий преимущественно в сознании.

Основной вывод, к которому можно прийти, заключается в том, что подсознание ближе к сознанию. Влияние подсознания на мыслительный процесс позволяет субъекту заглянуть в его сферу. Установки, через которые подсознание влияет на мыслительный процесс, путем рефлексии могут быть репрезентированы в сознание, где в последующем субъект может их проанализировать. Возможность предоставления из подсознания инициирующих мыслительный акт установок существует в случае, когда мыслительный акт может быть построен благодаря элементам подсознания (мыслительные акты, требующие творческого подхода).

Если принять точку зрения, что подсознание - часть психики субъекта, которая позволяет хранить не обработанную сознанием информацию, прошедшую через процесс восприятия, а также работает с чувственными и эмоциональными образами субъекта, то представляется очевидным, что мышление как сознательный процесс не может подвергаться влиянию бессознательного.

Бессознательное не способно влиять на сознательные процессы наравне с подсознанием, так как оно позволяет утаить большинство процессов мозга от ментального пространства субъекта, оно разгружает всю психику субъекта. Бессознательное есть некое компенсаторное явление, препятствующее тому, чтобы в сознание были репрезентированы все психофизические и физиологические процессы мозга и организма, в противном случае сознание было бы занято обработкой миллионов процессов, происходящих в нашем организме. Ограждение от абсолютно не важной для психической жизни субъекта информации дает возможность психике субъекта полноценно функционировать.

Таким образом, следует признать, что понятие бессознательного является избыточным для анализа психики субъекта. Подсознание может работать, проявляя себя сознанию субъекта, оно обладает способностью

${ }^{11}$ Гартли Д. Размышление человеке, его строении, его долге и упованиях // Английские материалисты XVIII века. - М.: Мысль, 1967. - Т. 2. 
влиять на мыслительные акты через предоставление установок, инициирующих построение мыслительного акта. Субъект может работать с материалом подсознания, когда он заинтересован в основании сформированной у него установки, в то время как информация из бессознательного не может быть репрезентирована в сознание.

Подсознание способно проявлять себя через влияние на сюжет сновидений. Подборка «картинок» или единый сюжет сновидения - это не более чем разгрузка психикой переработанной за предшествующий день или ранее информации. Состояние сна, когда сознание пребывает в не загруженном актуальным содержанием состоянии, когда не поступает информация извне, - благотворная среда для подсознания. Именно во сне подсознание не испытывает такого жесткого подавления со стороны сознания, за счет чего оно способно придавать сновидениям весьма необычный сюжет. Судя по всему, бессознательное состояние не проявляется даже в состоянии сна, так как оно не обладает содержанием, аналогичным содержанию подсознания или сознания. Информация, находящаяся за границей, которую проводит бессознательное между метальным миром субъекта и физиологическими процессами, не может быть конвертирована в образы, установки, симпатии и антипатии.

Для того чтобы лучше понять, почему невозможно влияние бессознательного на мыслительный процесс, целесообразно сравнить взаимодействие бессознательного и ментального с работой компьютера (вычислительной машины). Для обоснования правомерности такого сравнения следует обратиться к теории функционализма. Согласно идее функционализма, нет онтологической разницы между вычислительными процессами, осуществляемыми головным мозгом и вычислительной машиной.

Функционализм сегодня является одной из самых влиятельных теорий, используемых для объяснения феномена сознания. Любое ментальное состояние он рассматривает прежде всего через отношения с сигналами входа и выхода, а также с иными ментальными состояниями. Идея о каузальности связей является основой функционалистской теории. Одним из наиболее влиятельных представителей функционализма сегодня считается Д. Деннет.

Применим функционалистскую аналогию к работе бессознательного и ментального. Допустим, что «сырая», неструктурированная информация о работе бессознательного может быть выведена в интерфейс, в данном случае в сознание. Результатом такого выведения станет проявление на уровне единиц и нолей или иных логических единиц, которые могут существенно затруднить для пользователя понимание обработан- 
ных и представленных данных. Информация с базовых уровней работы вычислительной машины необходима для отслеживания показателей температуры, для контроля загруженности процессора и т.д. Эти показатели могут быть выведены в интерфейс, но по своей сути являются агрегированными макропоказателями. Информационные слои подобного рода отгорожены от пользователя и практически никогда не нужны ему непосредственно. Субъект нуждается в качественном осуществлении процессов, которое обусловлено базовыми уровнями работы компьютера. Пользовательская потребность заключается в наличии оперативно работающего интерфейса. Однако удовлетворительную работу интерфейса обусловливает оперативная работа вычислительной машины (компьютера). Пользователь может не догадываться о процессах, протекающих в базовых уровнях компьютера, а «голая» информация, извлеченная из указанных слоев, не откроет для него ничего нового.

Проводя эту аналогию, когда мы рассматриваем работу организма, можно обнаружить, что бессознательное, как указывалось ранее, отгораживает от сознания осуществление функций организма таким образом, что субъект может комфортно функционировать в рамках нормы. Субъект обладает возможностью отследить свою температуру или понять, что организм болен, таким образом косвенно «вытаскивает» информацию о протекании бессознательного процесса, отклонившегося от нормы. Однако доступ к более содержательной информации для субъекта закрыт.

Бессознательное укрывает от нашего ментального мира миллионы параллельных вычислений, которые происходят в головном мозге, его содержание представляется нашему сознанию хаосом. Согласно Дж. Серлю, «нет никакой интенциональной каузальности, внутренне присущей системе» ${ }^{12}$ [Серл, 2002. - С. 131]. Серьезным следствием такого утверждения является отказ осмысленным бессознательным процессам в онтологическом статусе.

Итак, можно сделать вывод, что понятие подсознания и понятие бессознательного отражают совершенно разные сущности. Использование понятие бессознательного при исследовании ментального мира представляется избыточным. Бессознательное не обладает никаким психическим содержанием. Попытки наделения бессознательного психическим содержанием приводят к ложному пониманию бессознательного, которое отгораживает физиологические процессы от процессов психиче-

\footnotetext{
${ }^{12}$ Серль Дж. Открывая сознание заново. - М.: Идея-Пресс, 2002. - С. 131.
} 
ских. Бессознательное вытеснено за границы ментального мира субъекта, оно не может оказывать влияние на психические процессы, такие как мышление.

Субъект имеет возможность по средствам рефлексии получить небольшие данные о том, что происходит в его подсознании, в то время как информация бессознательного не конвертируема в область психики. Бессознательное не способно оказывать влияние на мыслительные процессы, как это делают подсознание или сознание, поскольку его функция не состоит в непосредственных хранении и обработке воспринятой информации.

Подсознание представляется частью психики, как и сознание. Следовательно, подсознание и сознание образуют некоторое единство. Подсознание существенно ближе по своей природе к сознанию, в то время как бессознательное скорее обусловливает качественную работу всех частей психики, но не примыкает ни к сознанию, ни к подсознанию. Подсознание позволяет осуществлять определенную разгрузку сознания, выполняя по отношению к нему компенсаторную функцию, благодаря которой сознание получает возможность избежать перегрузки. Мышление как психический продуктивный процесс испытывает влияние только со стороны сознания и подсознания. Если на мыслительный процесс влияет подсознание, то это влияние осуществляется посредством предоставления установок, которые формируются в области подсознания.

\section{Литература}

Винник Д.В. Сознание за пределами мозга: Истоки аргументации радикального экстернализма // Вестник ТГУ. Сер.: Философия. Социология. Политология. - 2010.- № 2.C. $125-136$.

Гартли Д. Размышление о человеке, его строении, его долге и упованиях // Английские материалисты XVIII века. - М.: Мысль, 1967. - Т. 2.

Деннет Д. Виды психики. - М.: Идея-Пресс. - 2004. - С. 58.

Дюеймс У. Психология. - М.: Педагогика. - 1991. - С. 250.

Зинченко В.П. Миры сознания и структура сознания // Вопросы психологии. - 1991. № 2. - C. 15 .

Лейбнии Г.В. Монадология // Лейбниц Г.В. Сочинения: В 4 т.- М.: Мысль, 1982.T. 1. - C. 415.

Серль Дж. Открывая сознание заново. - М.: Идея-Пресс, 2002. - С. 131.

Спиноза Б. Этика. - СПб.: Азбука. - 2015. - С. 173.

Юнг К.Г. Аналитическая психология: Тавистокские лекции. - СПб.: Кентавр, 1994.C. 35 .

Clark A., Chalmers D. The extended mind // Analysis. - 1998. - No. 58 (1). - P. 7-19. 


\section{References}

Vinnik D.V. Soznanie za predelami mozga. Istoki argymentacii radikalnogo externalizma// Vestnik TGU. Ser.: Filosofia. Sociologia. Politologya. - 2010. - № 2. - C. 125-136.

Gartly D. Rasmishlenye o cheloveke, ego stroenii, ego dolge I ypovanyakh // Anglyiskie materialisti XVIII. - M., 1967. - T. 2.

Dennet D. Vyidi psichiki. - M.: Ideya-Press, 2004.

James У. Psichologya. - M.: Pedagogika. - 1991.

C. 15-36.

Zinchenko V.P. Myiri soznania I stryltyra soznaniya // Voprosi psichologii. - 1991. - № 2. -

Leybniz G.V. Sochinenya v chetirech tomach. - M.: Misl. - 1982. - T. 1. - C. 413-429.

Searle. J. Otkryvaya soznanye zanovo. - M.: Ideya-Press, 2002.

Spinoza B. Etyika. - СПб.: Azbyka, 2015.

Jung K.G. Anyliticheskaya psichologya. Tavistockskie lekcii. - СПб.: Kentavr, 1994.

Clark A., Chalmers D. The extended mind // Analysis. - 1998. - № 58 (1). - P. 7-19.

Дата поступления 28.08.2015 